\title{
BMJ
}

\section{Association of door-to-balloon time and mortality in patients admitted to hospital with ST elevation myocardial infarction: national cohort study}

\author{
Saif S Rathore, MD/PhD student,, Jeptha P Curtis, assistant professor, ${ }^{2}$ Jersey Chen, assistant professor, ${ }^{2}$ \\ Yongfei Wang, statistician, ${ }^{3}$ Brahmajee K Nallamothu, assistant professor, ${ }^{4}$ Andrew J Epstein, assistant \\ professor, ${ }^{5}$ Harlan M Krumholz, Harold H Hines Jr professor of medicine (cardiology) and epidemiology and \\ public health, ${ }^{2,3,6}$ for the National Cardiovascular Data Registry
}

${ }^{1} \mathrm{MD} / \mathrm{PhD}$ Program, Yale University School of Medicine, 367 Cedar Street, 316 ESH, New Haven, Connecticut 06510

${ }^{2}$ Section of Cardiovascular Medicine, Department of Internal Medicine, Yale University School of Medicine, 333 Cedar Street,

3 FMP, PO Box 208017, New Haven, Connecticut 06520

${ }^{3}$ Center for Outcomes Research and Evaluation, Yale-New Haven Hospital, One Church Street, Suite 200, New Haven, Connecticut 06510

${ }^{4}$ Cardiovascular Center, CVC Cardiovascular Medicine,

University of Michigan Medical School, SPC 5869, 1500 E

Medical Center Drive, Ann Arbor, Michigan 48109

${ }^{5}$ Section of Health Policy and Administration, Yale School of Public Health, 60 College Street, Room 301, PO Box 208034 , New Haven, Connecticut 06520

${ }^{6}$ Robert Wood Johnson Clinical Scholars Program, Yale University School of Medicine,

PO Box 208088, New Haven, Connecticut 06520

Correspondence to: S S Rathore saif.rathore@yale.edu

Cite this as: BMJ 2009:338:b1807 doi:10.1136/bmi.b1807

\section{ABSTRACT}

Objective To evaluate the association between door-toballoon time and mortality in hospital in patients undergoing primary percutaneous coronary intervention for ST elevation myocardial infarction to assess the incremental mortality benefit of reductions in door-toballoon times of less than 90 minutes.

Design Prospective cohort study of patients enrolled in the American College of Cardiology National

Cardiovascular Data Registry, 2005-6.

Setting Acute care hospitals.

Participants 43801 patients with ST elevation myocardial infarction undergoing primary percutaneous coronary intervention.

Main outcome measure Mortality in hospital.

Results Median door-to-balloon time was 83 minutes (interquartile range 6-109, 57.9\% treated within 90 minutes). Overall mortality in hospital was $4.6 \%$. Multivariable logistic regression models with fractional polynomial models indicated that longer door-to-balloon times were associated with a higher adjusted risk of mortality in hospital in a continuous non-linear fashion (30 minutes $=3.0 \%, 60$ minutes $=3.5 \%, 90$ minutes $=4.3 \%$, 120 minutes $=5.6 \%, 150$ minutes $=7.0 \%, 180$ minutes $=8.4 \%, P<0.001)$. A reduction in door-to-balloon time from 90 minutes to 60 minutes was associated with $0.8 \%$ lower mortality, and a reduction from 60 minutes to 30 minutes with a $0.5 \%$ lower mortality.

Conclusion Any delay in primary percutaneous coronary intervention after a patient arrives at hospital is associated with higher mortality in hospital in those admitted with ST elevation myocardial infarction. Time to treatment should be as short as possible, even in centres currently providing primary percutaneous coronary intervention within 90 minutes.

\section{INTRODUCTION}

Clinical guidelines recommend that hospitals providing primary percutaneous coronary intervention to patients with ST segment elevation myocardial infarction should treat patients within 90 minutes of contact with the medical system or admission to hospital. ${ }^{1}$ Although most studies point to an independent association between longer time to treatment and higher mortality, the specific shape of the relation between mortality risk and time to treatment is unclear. While some studies indicate that any delay after admission is associated with higher mortality, ${ }^{2-11}$ others suggest mortality is higher only after an initial delay in treatment of an hour or more. ${ }^{12}{ }^{13}$ In addition, it is unclear whether mortality is higher with successively longer times to treatment, ${ }^{2-69101213}$ or if mortality eventually plateaus after two or more hours of delay. ${ }^{7111415}$

Clarifying the specific shape of the association between door-to-balloon time (that is, between arrival at hospital and treatment) and mortality is important given recent efforts to reduce delays. Current quality improvement initiatives, such as the Door-to-Balloon Alliance, seek to achieve a door-to-balloon time of 90 minutes or less among $75 \%$ or more of patients undergoing primary percutaneous coronary intervention at participating hospitals. ${ }^{16}$ Several hospitals have shown that it is possible to push beyond this benchmark and achieve median door-to-balloon times approaching 60 minutes. ${ }^{17}$ Relatively little data exist regarding the incremental benefit of further reductions beyond 90 minutes.

We analysed data from the American College of Cardiology National Cardiovascular Data Registry, a large national database containing detailed medical records of community patients undergoing percutaneous coronary intervention. We hypothesised that any increase in door-to-balloon time would be associated with increased mortality and that this mortality risk would persist irrespective of the length of the delay in treatment.

\section{METHODS}

National Cardiovascular Data Registry

The registry, described in detail elsewhere, is sponsored by the American College of Cardiology and contains details of patients undergoing cardiac 
Table 1|Distribution of door-to-balloon time in patients undergoing primary percutaneous coronary intervention for ST elevation myocardial infarction

\begin{tabular}{lc} 
Time (minutes) & Proportion of cohort (No) \\
$\leq 30$ & $3.2(1396)$ \\
\hline $31-60$ & $19.6(8575)$ \\
\hline $61-90$ & $35.1(15388)$ \\
\hline $91-120$ & $23.3(10208)$ \\
\hline $121-150$ & $9.8(4283)$ \\
\hline $151-180$ & $4.2(1856)$ \\
\hline $181-210$ & $2.0(895)$ \\
\hline $211-240$ & $1.1(469)$ \\
\hline$\geq 241$ & $1.7(731)$
\end{tabular}

catheterisation at more than 600 participating centres in the United States. Sites were encouraged to prospectively collect detailed clinical information including medical history, indications for procedure, angiographic findings, treatment, events, and procedural outcomes, from all patients undergoing cardiac catheterisation. Data quality was ensured through the use of standardised data elements and definitions, systematic data entry with common registry software, an onsite audit programme, and transmission to a central data warehouse for additional review before analysis.

\section{Study sample}

We limited our analysis to patients who, in 2005-6, presented to a participating centre within 12 hours of symptom onset with laboratory and electrocardiographic evidence of ST elevation myocardial infarction and subsequently underwent primary percutaneous coronary intervention $(n=64676)$. We excluded patients who were transferred from other hospitals $(n=17992)$ because we could not evaluate their status on admission. We also excluded patients who first received fibrinolytic therapy and were subsequently referred for primary percutaneous coronary intervention $(\mathrm{n}=3313)$. Patients under 18 years or over 99 years $(n=9)$ were excluded to focus analysis on adult

Table 2| Patients' characteristics and door-to-balloon time in patients undergoing primary percutaneous coronary intervention for ST elevation myocardial infarction. Figures are percentages of patients unless stated otherwise

\begin{tabular}{|c|c|c|c|c|c|c|c|}
\hline \multirow[b]{2}{*}{ Characteristic } & \multirow[b]{2}{*}{ Overall } & \multicolumn{4}{|c|}{ Door-to-balloon time (minutes) } & \multirow[b]{2}{*}{ Overall P } & \multirow[b]{2}{*}{ P for trend } \\
\hline & & $<60$ & $60-89$ & $90-119$ & $\geq 120$ & & \\
\hline No of patients & 43801 & 9971 & 15388 & 10208 & 8234 & - & 一 \\
\hline \multicolumn{8}{|l|}{ Demographics: } \\
\hline Median age (IQR) & $59(51-70)$ & $58(51-68)$ & $59(51-69)$ & $60(51-71)$ & $61(52-73)$ & $<0.001$ & $<0.001$ \\
\hline Women & 27.9 & 24.8 & 25.8 & 29.2 & 34.0 & $<0.001$ & $<0.001$ \\
\hline White race & 84.7 & 86.3 & 85.5 & 84.2 & 81.8 & $<0.001$ & $<0.001$ \\
\hline \multicolumn{8}{|l|}{ Medical history: } \\
\hline Previous myocardial infarction & 18.3 & 16.5 & 17.4 & 19.4 & 21.1 & $<0.001$ & $<0.001$ \\
\hline Previous heart failure & 4.1 & 3.0 & 3.3 & 4.5 & 6.6 & $<0.001$ & $<0.001$ \\
\hline Diabetes & 20.0 & 17.5 & 18.4 & 21.1 & 24.9 & $<0.001$ & $<0.001$ \\
\hline Renal failure & 2.4 & 1.6 & 2.0 & 2.6 & 4.0 & $<0.001$ & $<0.001$ \\
\hline Hypertension & 59.0 & 55.2 & 57.1 & 60.3 & 65.4 & $<0.001$ & $<0.001$ \\
\hline Cerebrovascular disease & 6.5 & 5.5 & 5.7 & 7.0 & 8.5 & $<0.001$ & $<0.001$ \\
\hline Peripheral vascular disease & 6.2 & 5.2 & 5.4 & 6.3 & 8.8 & $<0.001$ & $<0.001$ \\
\hline Current tobacco use & 44.1 & 46.2 & 45.4 & 43.8 & 39.4 & $<0.001$ & $<0.001$ \\
\hline Chronic lung disease & 11.5 & 10.7 & 10.8 & 11.8 & 13.5 & $<0.001$ & $<0.001$ \\
\hline Dyslipidaemia & 57.3 & 57.4 & 56.8 & 57.4 & 57.9 & 0.083 & 0.38 \\
\hline $\begin{array}{l}\text { Family history of early onset } \\
\text { CAD }\end{array}$ & 23.3 & 24.1 & 22.9 & 23.2 & 23.0 & 0.28 & 0.16 \\
\hline Previous $\mathrm{PCl}$ & 19.3 & 18.4 & 18.3 & 20.2 & 20.9 & $<0.001$ & $<0.001$ \\
\hline Previous CABG & 5.7 & 3.2 & 4.4 & 6.9 & 9.7 & $<0.001$ & $<0.001$ \\
\hline \multicolumn{8}{|l|}{ Admission findings: } \\
\hline $\begin{array}{l}\text { Admitted }<6 \text { hours after } \\
\text { symptom onset }\end{array}$ & 90.9 & 92.4 & 92.6 & 90.8 & 86.4 & $<0.001$ & $<0.001$ \\
\hline Heart failure on admission & 8.4 & 6.8 & 7.2 & 8.7 & 12.1 & $<0.001$ & $<0.001$ \\
\hline Cardiogenic shock & 9.5 & 8.6 & 8.9 & 9.6 & 11.7 & $<0.001$ & $<0.001$ \\
\hline \multicolumn{8}{|l|}{ NYHA class: } \\
\hline 1 & 24.2 & 26.3 & 23.5 & 23.4 & 23.8 & \multirow{4}{*}{$<0.001$} & \multirow{4}{*}{-} \\
\hline II & 5.8 & 5.6 & 5.2 & 6.2 & 6.8 & & \\
\hline III & 15.7 & 14.7 & 15.5 & 16.2 & 16.7 & & \\
\hline IV & 54.3 & 53.4 & 55.9 & 54.2 & 52.6 & & \\
\hline
\end{tabular}

$I Q R=$ interquartile range, $C A D=$ coronary artery disease, $P C l=$ percutaneous coronary intervention, $C A B G=$ coronary artery bypass graft, $N Y H A=N$ ew $Y o r k$ Heart Association. 
Table 3 |Procedural characteristics and door-to-balloon time in patients undergoing primary percutaneous coronary intervention for ST elevation myocardial infarction. Figures are percentages of patients unless stated otherwise

\begin{tabular}{|c|c|c|c|c|c|c|c|}
\hline & \multirow[b]{2}{*}{ Overall } & \multicolumn{4}{|c|}{ Door-to-balloon time (minutes) } & \multirow[b]{2}{*}{ Overall P } & \multirow[b]{2}{*}{ P for trend } \\
\hline & & $<60$ & $60-89$ & $90-119$ & $\geq 120$ & & \\
\hline No of patients & 43801 & 9971 & 15388 & 10208 & 8234 & - & - \\
\hline Weekend procedure & 28.2 & 17.0 & 28.2 & 34.7 & 33.7 & $<0.001$ & $<0.001$ \\
\hline \multicolumn{8}{|l|}{ Time of presentation: } \\
\hline Weekday 0000-0759 & 17.0 & 11.2 & 16.7 & 20.5 & 20.2 & \multirow{6}{*}{$<0.001$} & \multirow{6}{*}{-} \\
\hline Weekday 0800-1559 & 32.8 & 52.8 & 31.9 & 21.9 & 23.6 & & \\
\hline Weekday 1600-2359 & 22.0 & 19.0 & 23.2 & 22.9 & 22.6 & & \\
\hline Weekend 0000-0759 & 6.6 & 3.1 & 6.0 & 9.4 & 8.7 & & \\
\hline Weekend 0800-1559 & 12.5 & 8.6 & 12.6 & 14.5 & 14.4 & & \\
\hline Weekend 1600-2359 & 9.0 & 5.3 & 9.5 & 10.8 & 10.5 & & \\
\hline \multicolumn{8}{|l|}{ Angiographic findings } \\
\hline Mean (SD) No of lesions & $1.3(0.6)$ & $1.3(0.6)$ & $1.3(0.6)$ & $1.3(0.6)$ & $1.4(0.7)$ & 0.035 & 0.022 \\
\hline \multicolumn{8}{|l|}{ Stenosis locations: } \\
\hline Left main & 2.7 & 2.2 & 2.7 & 2.8 & 3.4 & $<0.001$ & $<0.001$ \\
\hline Left anterior descending & 55.0 & 51.4 & 54.0 & 56.2 & 59.6 & $<0.001$ & $<0.001$ \\
\hline Circumflex & 33.3 & 29.8 & 31.8 & 34.6 & 38.4 & $<0.001$ & $<0.001$ \\
\hline Right coronary artery & 59.8 & 60.7 & 60.5 & 59.9 & 57.4 & $<0.001$ & $<0.001$ \\
\hline IABP used & 10.8 & 10.0 & 10.4 & 11.0 & 12.4 & $<0.001$ & $<0.001$ \\
\hline Thrombin inhibitors & 10.8 & 11.3 & 10.7 & 9.9 & 11.4 & 0.003 & 0.61 \\
\hline Non-stent device used & 90.6 & 91.8 & 91.4 & 90.2 & 88.1 & $<0.001$ & $<0.001$ \\
\hline \multicolumn{8}{|l|}{ SCAl classification: } \\
\hline Not reported & 0.5 & 0.4 & 0.5 & 0.6 & 0.7 & \multirow{5}{*}{$<0.001$} & \multirow{5}{*}{-} \\
\hline 1 & 16.5 & 14.1 & 15.6 & 17.6 & 19.6 & & \\
\hline II & 19.6 & 17.2 & 18.9 & 21.1 & 22.1 & & \\
\hline III & 21.2 & 23.3 & 21.8 & 20.0 & 18.8 & & \\
\hline IV & 42.2 & 45.0 & 43.2 & 40.6 & 38.7 & & \\
\hline
\end{tabular}

$\mid \mathrm{ABP}=$ intra-aortic balloon pump, SCAI=Society for Cardiac Angiography and Interventions.

patients suitable for primary percutaneous coronary intervention. Finally, to minimise data coding errors, we excluded patients treated at hospitals that reported fewer than five primary percutaneous coronary interventions $(\mathrm{n}=29)$. A total of 18989 patients met one or more of the above exclusion criteria, leaving 45687 patients eligible for analysis.

\section{Door-to-balloon time}

Door-to-balloon time was defined as the time in minutes between a patient's arrival at the hospital and the first balloon inflation or device deployment as documented in the patient's medical record. For the purpose of evaluating differences in patients' characteristics associated with time to treatment we divided patients into four groups: $<60,60-89,90-119$, and $\geq 120$ minutes. For all other analyses, we modelled door-to-balloon time as a continuous variable.

Of the 45687 patients eligible for analysis, we excluded 503 for whom door-to-balloon time was missing. Patients with a door-to-balloon time $<15$ minutes ( $\mathrm{n}=971$ ) were excluded to avoid potentially incorrectly coded times. Patients with a door-toballoon time $>6$ hours $(n=915)$ were also excluded because they presumably did not receive percutaneous coronary intervention as a primary reperfusion strategy. The final study sample therefore consisted of 43801 patients.

\section{Statistical analysis}

We first determined the mean, median, and distribution of door-to-balloon times. Differences in patients' demographic and clinical characteristics were compared across the four door-to-balloon time groups with $\chi^{2}$ tests and trend analyses for categorical variables and analyses of variance for continuous variables.

We conducted logistic regression analysis using fractional polynomial modelling to determine the specific shape of the unadjusted association between door-toballoon time and mortality in hospital. Fractional polynomial modelling compares models of different combinations of linear and non-linear transformations of door-to-balloon time to identify those models that best reflect the association of time to treatment and mortality. We identified best fitting transformations by comparison of model deviances using a $\chi^{2}$ distribution with 1 degree of freedom.

We repeated analyses adjusting for patients' characteristics associated with mortality derived from the registry mortality model. ${ }^{18}$ Variables included sex, race, age, findings at presentation (shock, renal failure, time from symptom onset to admission), medical history (diabetes, left ventricular ejection fraction, chronic 
lung disease), procedural characteristics (pre-procedure intra-aortic balloon pump, use of non-stent device, use of thrombin inhibitors, time of day, weekend procedure), and angiographic findings (left main disease, proximal left anterior descending lesion, Society of Cardiac Angiography and Intervention lesion classification ${ }^{19}$ ). In addition, we adjusted for hospital characteristics, including annual primary percutaneous coronary intervention volume, teaching status, ownership, and rural location.

To assess the robustness of our findings, we repeated analyses excluding patients who arrived in shock because time to treatment might be less important for patients who do not present in shock. ${ }^{20}$ To further reduce sample heterogeneity, we repeated analyses in the cohort of patients who presented within six hours of symptom onset.

Logistic regression models accounted for clustering of patients by hospital with Huber-White robust estimates of standard error. Statistical analyses were conducted with SAS 9.1 (SAS Institute, Cary, NC) and StataSE 9.0 (Stata Corporation, College Station, TX).

\section{RESULTS}

The median door-to-balloon time in the study cohort was 83 minutes (interquartile range 62-109 minutes), with 25359 patients $(57.9 \%)$ treated within 90 minutes of admission (table 1). A greater proportion of patients who had longer door-to-balloon times were women, non-white, and, on average, older than patients with shorter door-to-balloon times. In general, patients with longer door-to-balloon times had more comorbidities than patients with shorter door-to-balloon times, including a higher prevalence of previous myocardial infarction, heart failure, diabetes, hypertension, peripheral vascular disease, and previous revascularisation. Patients with shorter door-to-balloon times had a lower incidence of cardiogenic shock and stenoses of the left main and left anterior descending arteries, and a greater proportion had Society of Cardiac Angiography and Intervention IV lesions. A greater proportion of patients with shorter door-to-balloon times were treated on a

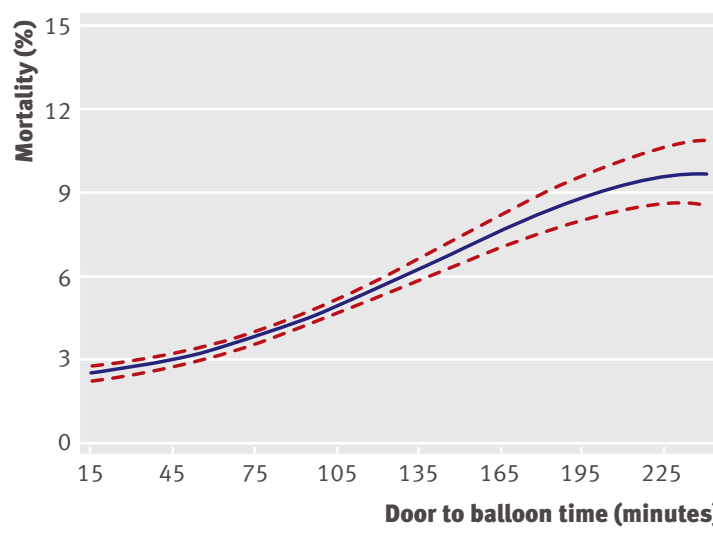

Fig 1 Unadjusted in hospital mortality as function of door-toballoon time (modelled as fractional polynomial) with $95 \%$ confidence intervals

weekday between 8 am and $4 \mathrm{pm}$ and at urban hospitals (tables 2-4).

Mortality in the study cohort was 4.6\% (1999/43 801) overall. Patients who died in hospital had a 14 minute longer median door-to-balloon time than patients who survived (96 v 82 minutes, $\mathrm{P}<0.001)$. Patients with longer door-to-balloon time groups had higher crude mortality across the four door-to-balloon time groups ( $<60$ minutes $=3.2 \%$ (323/9971), 60-89 minutes $=3.7 \%$ (568/15388), 90-119 minutes $=4.6 \% \quad$ (473/10 208), $\geq 120$ minutes $=7.7 \%$ (635/8234), $\mathrm{P}<0.001$ for trend).

Logistic regression analysis with a third degree fractional polynomial (door-to-balloon time, door-to-balloon time ${ }^{2}$, and door-to-balloon time ${ }^{3}$ ) best modelled the unadjusted association of door-to-balloon time with mortality, showing an increased risk of mortality associated with any delay in door-to-balloon time (fig 1). Estimated unadjusted mortality ranged from $2.8 \%$ for patients with door-to-balloon times of 30 minutes to $9.8 \%$ for patients with door-to-balloon times of 240 minutes (table 5).

Longer door-to-balloon times continued to be associated with increased mortality after multivariable adjustment (fig 2). A third degree fractional polynomial model continued to provide the best fit for the

Table 4 | Hospital characteristics and door-to-balloon time in patients undergoing primary percutaneous coronary intervention for ST elevation myocardial infarction. Figures are percentages of patients unless stated otherwise

\begin{tabular}{|c|c|c|c|c|c|c|c|}
\hline \multirow[b]{2}{*}{ Characteristic } & \multirow[b]{2}{*}{ Overall } & \multicolumn{4}{|c|}{ Door-to-balloon time (minutes) } & \multirow[b]{2}{*}{ Overall P } & \multirow[b]{2}{*}{ P for trenc } \\
\hline & & $<60$ & $60-89$ & $90-119$ & $\geq 120$ & & \\
\hline No of patients & 43801 & 9971 & 15388 & 10208 & 8234 & - & - \\
\hline $\begin{array}{l}\text { Median annual primary PCI } \\
\text { volume (IQR) }\end{array}$ & $144(89-215)$ & $145(91-238)$ & $146(91-215)$ & $143(87-214)$ & $135(82-210)$ & $<0.001$ & $<0.001$ \\
\hline Hospital data unavailable & 3.3 & 3.6 & 3.4 & 3.1 & 3.0 & 0.06 & 0.006 \\
\hline Rural hospital & 0.5 & 0.5 & 0.5 & 0.7 & 0.5 & 0.20 & 0.83 \\
\hline Teaching hospital & 48.7 & 51.2 & 48.3 & 47.3 & 48.2 & $<0.001$ & $<0.001$ \\
\hline \multicolumn{8}{|l|}{ Ownership: } \\
\hline Public & 8.2 & 7.9 & 8.3 & 8.0 & 8.4 & \multirow{3}{*}{$<0.001$} & \multirow{3}{*}{-} \\
\hline Not for profit & 82.2 & 82.2 & 82.6 & 82.3 & 81.4 & & \\
\hline For profit & 6.3 & 6.3 & 5.6 & 6.5 & 7.3 & & \\
\hline
\end{tabular}

$\mathrm{PCl}=$ percutaneous coronary intervention, $\mathrm{IQR}=$ interquartile range. 


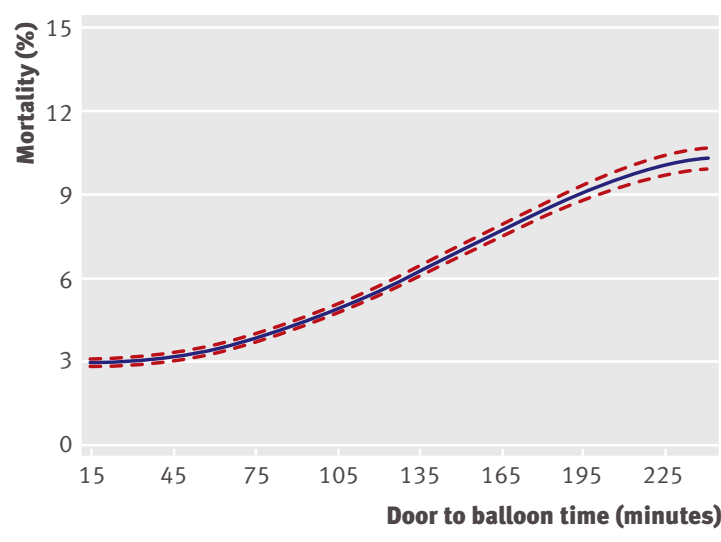

Fig 2 Adjusted in hospital mortality as function of door-toballoon time (modelled as fractional polynomial) with $95 \%$ confidence intervals

adjusted association of door-to-balloon time with mortality, with any delay in door-to-balloon time continuing to be associated with an increased mortality risk. Estimated adjusted mortality ranged from 3.0\% for patients with door-to-balloon time of 30 minutes to $10.3 \%$ for patients with door-to-balloon times of 240 minutes (table 5).

Findings were similar when we repeated analyses excluding the 4166 patients who presented in shock. In the 39635 patients without shock, longer door-toballoon times continued to be associated with higher crude mortality $(<60$ minutes $=1.7 \%$ (156/9111), $60-89$ minutes $=1.8 \%$ (247/14 024), 90-119 minutes $=2.2 \%$ (203/9226), $\geq 120$ minutes $=3.6 \% \quad(262 / 7274)$, $\mathrm{P}<0.001$ for trend). A third degree fractional polynomial model also provided the best fit for the adjusted association of door-to-balloon times with mortality in patients without shock, with any increase in door-to-

Table 5 | Estimated in hospital mortality ( $95 \%$ confidence interval) by door-to-balloon time in patients undergoing primary percutaneous coronary intervention for ST elevation myocardial infarction

\begin{tabular}{llc} 
Time (minutes) & Unadjusted & Adjusted* \\
\hline 15 & $2.6(2.3$ to 2.8$)$ & $2.9(2.8$ to 3.1$)$ \\
\hline 30 & $2.8(2.5$ to 3.0$)$ & $3.0(2.9$ to 3.2$)$ \\
\hline 65 & $3.1(2.8$ to 3.3$)$ & $3.2(3.1$ to 3.3$)$ \\
\hline 75 & $3.4(3.2$ to 3.7$)$ & $3.5(3.4$ to 3.6$)$ \\
\hline 10 & $3.9(3.7$ to 4.1$)$ & $3.8(3.7$ to 4.0$)$ \\
\hline 120 & $4.4(4.2$ to 4.6$)$ & $4.3(4.2$ to 4.4$)$ \\
\hline 135 & $5.0(4.8$ to 5.2$)$ & $4.9(4.8$ to 5.0$)$ \\
\hline 150 & $5.6(5.4$ to 6.0$)$ & $5.6(5.4$ to 5.7$)$ \\
\hline 165 & $6.3(6.0$ to 6.7$)$ & $6.3(6.1$ to 6.4$)$ \\
\hline 180 & $7.0(6.6$ to 7.5$)$ & $7.0(6.8$ to 7.2$)$ \\
\hline 195 & $7.7(7.2$ to 8.3$)$ & $7.7(7.5$ to 8.0$)$ \\
\hline 210 & $8.4(7.7$ to 9.1$)$ & $8.4(8.2$ to 8.7$)$ \\
\hline 225 & $8.9(8.2$ to 9.8$)$ & $9.1(8.8$ to 9.4$)$ \\
\hline 240 & $9.4(8.5$ to 10.3$)$ & 9.7 (9.3 to 10.0$)$ \\
\hline
\end{tabular}

*Adjusted for sex, age, race, findings on presentation, medical history, procedural characteristics, angiographic findings, and hospital factors. balloon time associated with increased mortality (results not shown).

\section{DISCUSSION}

Any delay in door-to-balloon time for patients with ST elevation myocardial infarction undergoing primary percutaneous coronary intervention is associated with higher mortality, even among patients treated within 90 minutes of admission. The mortality risk with door-to-balloon time persists irrespective of the length of the treatment delay. Our data suggest that physicians could reduce mortality among such patients by minimising door-to-balloon time to the greatest extent possible, even among those treated within times recommended by guidelines.

\section{Comparison with other studies}

Our analysis improves on previous studies that modelled time to treatment as a categorical ${ }^{457810-1420-24}$ or continuous linear variable. ${ }^{239}$ Use of categorical variables might result in a loss of statistical power, which could explain why certain studies report no increased risk associated with delayed time to treatment. ${ }^{20-24}$ Alternatively, by modelling time to treatment as a linear continuous variable, previous analyses assumed each additional delay in treatment was associated with the same additional increased risk in mortality, which is not necessarily true. ${ }^{25}$ Neither approach accounts for the possibility that the mortality risk associated with time to treatment might vary over time. By using fractional polynomial regression, we assessed the association of door-to-balloon time and mortality using statistical modelling techniques that made no assumptions regarding the shape of the association between time to treatment and mortality.

Our principal finding of an immediate increase in mortality associated with any delay in door-to-balloon time reconciles competing reports concerning the shape of the mortality risk associated with delayed primary percutaneous coronary intervention. While some studies found that increased mortality associated with delays were present solely within the first few hours of presentation and then plateaued, ${ }^{714}$ others had suggested the reverse - a risk that was initially unchanged and increased only after a few hours of delay. ${ }^{12} 13$ Our study suggests that both reports might be correct in that the mortality risk associated with any delay in time to treatment might be present immediately after admission and persist for several hours. A closer assessment of previous studies indicates that many, in fact, suggest such a consistent trend of increased mortality with any delay in time to treatment. For instance, although Cannon and colleagues reported that mortality associated with longer doorto-balloon time manifested after two or more hours of delay, there is a clear trend towards increased mortality in patients with door-to-balloon times of 61-90 minutes and 91-120 minutes. ${ }^{13}$ Furthermore, the few studies that have also modelled time to treatment as a continuous variable have similarly shown increases in adverse outcomes associated with any delay in 


\section{WHAT IS ALREADY KNOWN ON THIS TOPIC}

Clinical guidelines recommend that hospitals providing primary percutaneous coronary intervention to patients with ST segment elevation myocardial infarction treat within 90 minutes of contact with the medical system or admission to hospital

The specific shape of the relation between mortality risk and time to treatment, and the incremental benefit of reductions in door-to-balloon times beyond 90 minutes, is unclear

\section{WHAT THIS STUDY ADDS}

Any delay in door-to-balloon time for patients with ST elevation myocardial infarction undergoing primary percutaneous coronary intervention is associated with higher mortality, even among patients treated within 90 minutes of admission

Reducing door-to-balloon time to the greatest extent possible for all patient, including those currently treated within 90 minutes of admission, might reduce mortality

treatment. ${ }^{23}$ As such, differences in study findings concerning the specific shape of the association of door-toballoon time and mortality largely reflect the manner in which different studies have modelled time to treatment rather than contradictory findings regarding the relation between time and outcomes.

\section{Pathophysiology of delayed time to treatment}

An increased mortality risk associated with delayed time to treatment in patients undergoing primary percutaneous coronary intervention is consistent with current pathophysiological models of myocardial infarction. Experimental models have shown that the continuous, progressive "wave front of necrosis" largely depends on the duration of ischaemia. ${ }^{26-29}$ Thus, patients with longer door-to-balloon times will experience longer periods of vessel occlusion, resulting in more ischaemia and greater necrosis than patients with shorter times to treatment. ${ }^{30}$ Although there might be benefits to reperfusion therapy performed after long delays, including improved ventricular remodelling and reduced susceptibility to arrhythmic events, ${ }^{31}$ our data suggest that these benefits do not offset the underlying myocardial necrosis and attendant processes resulting from longer delays in time to treatment. ${ }^{32}$ This hypothesis is supported by the observation that patients transferred for primary percutaneous coronary intervention achieve similar rates of normal complete antegrade perfusion (TIMI 3 flow) as patients who are not transferred but have larger infarcts and poorer myocardial salvage. ${ }^{33}$

\section{Implications for practice}

We believe our finding that any minute of delay in treatment is associated with an increased risk of mortality has important implications for clinical practice. Notably, our data suggest that there is no "floor" to the mortality reduction that can be achieved by reducing time to treatment. As such, further reductions in door- to-balloon times, even below the 90 minute benchmark endorsed by clinical practice guidelines, offer the potential to significantly reduce mortality. For instance, our data show that reducing average doorto-balloon times from 90 minutes to 60 minutes might reduce in hospital mortality by as much as $0.8 \%$ (from $4.3 \%$ to $3.5 \%$ ). A further 30 minute reduction in door-to-balloon to an average of 30 minutes offers the potential of an additional $0.5 \%$ reduction (from 3.5\% to 3.0\%), underscoring the non-linear relation between time to treatment and mortality. Rather than accepting a 90 minute door-to-balloon time benchmark for primary percutaneous coronary intervention, our data support calls for an "as soon as possible" standard for patients undergoing primary percutaneous coronary intervention. ${ }^{34}$ Such an approach, using necessary safeguards against inappropriate treatment, offers the potential for notable reductions in mortality.

\section{Study limitations}

Our study has several limitations that merit consideration. Firstly, we were unable to assess the association of time from the onset of symptoms to arrival at hospital and mortality or the association of total ischaemic time and mortality. We attempted to limit this effect by conducting a secondary analysis restricted to patients who presented within six hours of symptom onset and found our results were similar. Furthermore, robust assessment of time from onset of symptoms to hospital admission might be problematic in that these times rely on patients' reports and thus cannot be independently verified, whereas door-to-balloon times are probably more accurately recorded. Secondly, we assessed the outcome of in hospital mortality and cannot comment on the association of door-to-balloon time and mortality at later end points. Previous studies, however, have reported that the association of door-to-balloon time and mortality is comparable whether assessed during hospital admission, at 30 days, or at one year. Finally, as our analysis was based on observational data our findings might be attributable to biases introduced by unmeasured factors. We attempted to mitigate this effect through robust risk adjustment but cannot preclude the possibility of residual confounding by other non-measured patient or hospital factors associated with door-to-balloon time or mortality.

\section{Conclusion}

Door-to-balloon time is associated with mortality in patients undergoing primary percutaneous coronary intervention for ST elevation myocardial infarction. Contrary to previous studies, we found that this risk was present on admission and was not attenuated with the passage of time, indicating that any delay in door-to-balloon time in such patients is associated with an increased mortality. As such, our findings suggest a benefit from reducing door-to-balloon time for all patients undergoing primary percutaneous coronary intervention, including those currently treated within 90 minutes of hospital admission. 
Contributors: SSR, JPC, JC, BKN, HMK were responsible for conception and design. HMK acquired the data, which were analysed and interpreted by all authors. SSR drafted the manuscript, which was critically revised by all authors. SSR and YW were responsible for statistical analyses. HMK obtained funding and supervised the study. JPC and HMK provided administrative, technical, and material support. SSR, YW, and HMK are guarantors

Funding and statement of independence from funding sources: This manuscript is the result of an unfunded analysis of the American College of Cardiology National Cardiovascular Data Registry. Although the sponsor was responsible for data collection, data management, and review of the manuscript before submission, they had no role in the design or conduct of this study, data analysis, interpretation of the data, manuscript preparation, or approval of the manuscript. SSR and JPC are supported, in part, by CTSA Grant Number UL1 RR024139 from the National Institutes of Health's Center for Research Resources. SSR is also supported by the National Institute of General Medical Sciences Medical Scientist Training Program grant 5T32GM07205.

Competing interests: None declared.

Ethical approval: Analysis of the American College of Cardiology National Cardiovascular Data Registry database was approved by the Yale University School of Medicine Human Investigation Committee, New Haven, Connecticut.

1 Antman EM, Hand M, Armstrong PW, Bates ER, Green LA, Halasyamani LK, et al. 2007 focused updated of the ACC/AHA 2004 guidelines for the management of patients with ST-elevation myocardial infarction: a report of the American College of Cardiology/ American Heart Association Task Force on Practice Guidelines (Writing Group to Review New Evidence and Update the ACC/AHA 2004 Guidelines for the Management of Patients with ST-Elevation Myocardial Infarction). I Am Coll Cardiol 2008:151:210-47.

2 De Luca G, van't Hof AW], de Boer M-J, Ottervanger JP, Hoorntje JC, Gosselink AT, et al. Time-to-treatment significantly affects the exten of ST-segment blush resolution and myocardial blush in patients with acute myocardial infarction treated by primary angioplasty. Eu Heart / 2004;25:1009-13.

3 De Luca G, Suryapranata H, Ottervanger JP, Antman EM. Time delay to treatment and mortality in primary angioplasty for acute myocardial infarction: every minute of delay counts. Circulation 2004;109:1223-5.

4 Berger PB, Ellis SG, Holmes DR Jr, Granger CB, Criger DA, Betriu A, et al. Relationship between delay in performing direct coronary angioplasty and early clinical outcome in patients with acute myocardial infarction. Circulation 1999;100:14-20.

5 Van't Hof AWJ, Liem A, Suryapranata H, Hoorntje JCA, de Boer M-J, Zijlstra F. Clinical presentation and outcome of patients with early, intermediate, and late reperfusion therapy by primary coronary angioplasty for acute myocardial infarction. Eur Heart 1998:19:118-123.

6 McNamara RL, Wang Y, Herrin J, Curtis JP, Bradley EH, Magid DJ, et al. Effect of door-to-balloon time on mortality in patients with STsegment elevation myocardial infarction. / Am Coll Cardiol 2006;47:2180-6.

7 Brodie BR, Stuckey TD, Wall TC, Kissling G, Hansen CJ, Muncy DB, et al. Importance of time to reperfusion for 30-day and late survival and recovery of left ventricular function after primary angioplasty for acute myocardial infarction. J Am Coll Cardiol 1998;32:1312-9.

8 Hudson MP, Granger CB, O'Neill WW, Stebbins AL, Widimsky P, Aylward P, et al. Faster times to primary percutaneous coronary intervention are associated with better survival: insights from the APEX-AMI trial [abstract]. / Am Coll Cardiol 2007;49:42-3B.

9 Nallamothu BK, Fox KAA, Kennelly BM, van de Werf F, Gore JM, Steg PJ, et al. Relationship of treatment delays and mortality in patients undergoing fibrinolysis and primary percutaneous coronary intervention: the Global Registry of Acute Coronary Events. Heart 2007;93:1552-5.

10 Brodie BR, Hansen C, Stuckey TD, Richter CS, Versteeg DS, Gupta N et al. Door-to-balloon time with primary percutaneous coronary intervention for acute myocardial infarction impacts late cardiac mortality in high-risk patients and patients presenting early after the onset of symptoms. J Am Coll Cardiol 2006;47:289-95.

11 Brodie BR, Stone GW, Cox DA, Stuckey TD, Turco M, Tcheng JE, et al. Impact of treatment delays on outcomes of primary percutaneous coronary intervention for acute myocardial infarction: analysis from the CADILLAC trial. Am Heart / 2006;151:1231-8.

12 Juliard J-M, Feldman LJ, Golmard J-L, Himbert D, Benamer H, Haghighat T, et al. Relation of mortality of primary angioplasty during acute myocardial infarction to door-to-Thrombolysis in Myocardial Infarction (TIMI) time. Am / Cardiol 2003;91:1401-5.

13 Cannon CP, Gibson CM, Lambrew CT, Shoultz DA, Levy D, French W], et al. Relationship of symptom-onset-to-balloon time and door-to- balloon time with mortality in patients undergoing angioplasty for acute myocardial infarction. JAMA 2000;283:2941-7.

14 Stone GW, O'Keefe J, Brodie BR, O'Neill WW, Grines CL. Lack of relationship between the time to reperfusion and short-term mortality after primary infarct angioplasty. I Am Coll Cardiol 1998;31:271A.

15 Brodie BR, Webb J, Cox DA, Qureshi M, Kalynych A, Turco M, et al. Impact of time to treatment on myocardial reperfusion and infarct size with primary percutaneous coronary intervention for acute myocardial infarction (from the EMERALD Trial). Am / Cardiol 2007;99:1680-6.

16 Krumholz HM, Bradley EH, Nallamothu BK, Ting HH, Batchelor WB, Kline-Rogers EE, et al. A campaign to improve the timeliness of primary percutaneous coronary intervention: door-to-balloon: an alliance for quality. IACC Cardiovasc Intverv 2008;1:97-104.

17 Rokos IC. Nine independent regional ST-elevation myocardial infarction networks exceed D2B alliance benchmark. / Am Coll Cardiol 2008;58:A379.

18 Shaw RE, Anderson HV, Brindis RG, Krone RJ, Klein LW, McKay CR, et al. Development of a risk adjustment mortality model using the American College of Cardiology-National Cardiovascular Data Registry (ACC-NCDR) experience: 1998-2000. J Am Coll Cardiol 2002;39:1104-12.

19 Krone RJ, Laskey WK, Johnson C, Kimmel SE, Klein LW, Weiner BH, et al. A simplified lesion classification for predicting success and complications of coronary angiography. Am J Cardiol 2000;85:1179-84.

20 Brodie BR, Stuckey TD, Muncy DB, Hansen CJ, Wall TC, Pulsipher M, et al. Importance of time-to-reperfusion in patients with acute myocardial infarction with and without cardiogenic shock treated with primary percutaneous coronary intervention. Am Heart J 2003;145:708-15.

21 De Luca G, Suryapranata H, Zijlstra F, van't Hof AW, Hoorntje JC, Gosselink AT, et al. Symptom-onset-to-balloon time and mortality in patients with acute myocardial infarction treated by primany angioplasty. J Am Coll Cardiol 2003;42:991-7.

22 Antoniucci D, Valenti R, Migliorini A, Moschi G, Trapani M, Buonamicic $\mathrm{P}$, et al. Relation of time to treatment and mortality in patients with acute myocardial infarction undergoing primary coronary angioplasty. Am J Cardiol 2002;89:1248-52.

23 Schömig A, Ndrepepa G, Mehilli I, Schwaiger M, Schühlen H, Nekolla S, et al. Therapy-dependent influence of time-to-treatment interval on myocardial salvage in patients with acute myocardial infarction treated with coronary artery stenting or thrombolysis. Circulation 2003;108:1084-8.

24 Brodie BR, Stone GW, Morice MC, Cox DA, Garcia E, Mattos LA, et al. Importance of time to reperfusion on outcomes with primary coronary angioplasty for acute myocardial infarction. Am / Cardiol 2001:188:1085-90

25 Gersh BJ, Stone GW, White HD, Holmes DR Jr. Pharmacological facilitation of primary percutaneous coronary intervention for acute myocardial infarction: is the slope of the curve the shape of the future? JAMA 2005;293:979-86.

26 Song YB, Hahn J-Y, Choi SM, Kim JH, Park YH, Choi S-H, et al.Time to reperfusion correlates to transmural extent rather than infarct size in primary percutaneous coronary angioplasty: contrast-enhanced magnetic resonance imaging analysis [abstract]. J Am Coll Cardiol 2008;51:A164.

27 Flameng W, Lesaffre E, Vanhaecke I. Determinants of infarct size in non-human primates. Basic Res Cardiol 1990;85:392-403.

28 Garcia-Dorado D, Théroux P, Elizaga J, Galiñanes M, Solares J, Riesgo M, et al. Myocardial reperfusion in the pig heart model: infarct size and duration of coronary occlusion. Cardiovasc Res 1987;21:537-44.

29 Reimer KA, Lowe JE, Rasmussen MM, Jennings RB. The wavefront phenomenon of ischemic cell death: myocardial infarct size vs. duration of coronary occlusion in dogs. Circulation 1977;56:786-94.

30 Stone GW, Dixon SR, Grines CL, Cox DA, Webb JG, Brodie BR, et al. Predictors of infarct size after primary coronary angioplasty in acute myocardial infarction from pooled analysis from four contemporary trials. Am / Cardiol 2007;100:1370-5.

$31 \mathrm{Kim} \mathrm{CB}$, Braunwald E. Potential benefits of late reperfusion of infarcted myocardium: the open artery hypothesis. Circulation 1993;88:2426-36

32 Gibson CM, de Lemos JA, Antman EM, from the TIMI Study Group. Time is muscle in primary PCl: the strength of the evidence grows. Eur Heart / 2004:25:1001-2.

33 Liem AL, van't Hof AWJ, Hoorntje JCA, de Boer M-J, Suryapranata H, Zijlstra F. Influence of treatment delay on infarct size and clinical outcome in patients with acute myocardial infarction treated with primary angioplasty. J Am Coll Cardiol 1998;32:629-33.

34 Williams DO. Treatment delayed is treatment denied. Circulation 2004:109:1806-8.

Accepted: 28 January 2009 